Fecha de recepción: mayo 2020 Fecha de aceptación: junio 2020 Versión final: julio 2020

\section{Introducción \\ Espacios de la ética y la identidad \\ en el quehacer del diseño \\ Marina Laura Matarrese ${ }^{(1)} y$ \\ Luz del Carmen Vilchis Esquivel ${ }^{(2)}$}

\begin{abstract}
Resumen: Esta edición de Cuadernos del Centro de Estudios en Diseño y Comunicación se inscribe dentro de la línea Investigar en Diseño. Precisamente, en este número se reúnen aportaciones académicas que establecen correlaciones epistemológicas en el amplio entramado de la ética, la identidad y el diseño, revisando convergencias y divergencias de las acciones de los diseñadores en el marco de un quehacer que busca establecer parámetros de conducta profesional. Los trabajos que conforman el presente volumen se han agrupado en tres ejes. Por un lado, las visiones éticas que reflexionan acerca de la práctica del diseño como ejercicio profesional en su articulación con pueblos indígenas y también con respecto a sus transformaciones históricas. Por el otro, las reflexiones teóricas acerca de la ética en el diseño, tanto en clave del ethos del diseñado, cuanto en relación con los desafíos que propone la posmodernidad y el mercado a dicho ethos. Por último, las disquisiciones en torno a la responsabilidad social y ética del diseño, proponen un análisis a los desafíos que conlleva éticamente la formación de nuevas generaciones de diseñadores en el ámbito universitario de grado y posgrado.
\end{abstract}

Palabras clave: ética - identidad - diseño - investigación.

[Resúmenes en inglés y portugués en la página 20]

(1) Investigadora del Consejo Nacional de Investigaciones Científicas y Técnicas (CONICETUBA). Directora del Doctorado en Diseño (Universidad de Palermo). Docente de Posgrado y Directora de la Línea Investigar en Diseño (UP). Integrante de numerosos equipos de investigación nacionales (PIP- CONICET, UBACYT, PICT- UBA) e internacionales (Papiit UNAM). Docente de grado en la Facultad de Filosofía y Letras (UBA). Dra. en Filosofía y Letras, Área Antropología de la Facultad de Filosofía y Letras de la Universidad de Buenos Aires. Especializada en temáticas de pueblos indígenas, estética, artesanía y territorio.

(2) Mexicana. Catedrática de la UNAM desde 1979 y miembro del Sistema Nacional de Investigadores nivel II. Su formación incluye: Licenciaturas en Diseño Gráfico, Filosofía y Psicología; Maestrías en Comunicación, Diseño Gráfico y Neuropsicología; Doctorados en Bellas Artes, Filosofía, Docencia y Filosofía Educativa. Autora de 44 libros, 40 capítulos, 152 artículos y manuales especializados. Directora de más de 275 tesis, ha dictado 95 cursos y 205 conferencias en 40 países. Directora de la Facultad de Artes y Diseño de la UNAM de 2002- 2006. Pionera en la aplicación de la tecnología digital a las artes y el diseño. Diseñadora profesional y artista visual. Reconocida con premios internacionales por su labor académica y de investigación. 
Esta edición de Cuadernos del Centro de Estudios en Diseño y Comunicación se inscribe dentro de la línea Investigar en Diseño. Precisamente, en este número se reúnen aportaciones académicas que establecen correlaciones epistemológicas en el amplio entramado de la ética, la identidad y el diseño, revisando convergencias y divergencias de las acciones de los diseñadores en el marco de un quehacer que busca establecer parámetros de conducta profesional. El diseño, desde esta perspectiva de investigación, se entiende como un conjunto de disciplinas cuyas perspectivas siempre inciden en la vida, la cotidianeidad y las costumbres de los seres humanos. Desde este encuadre, la premisa ética es transformada en códigos tácitos o expresos que norman al diseñar y a los diseñadores. De allí que, el objeto de estudio sea extenso, abundante y complicado.

Toda reflexión acerca de la conducta de los diseñadores atañe a la dimensión ética, rama de la filosofía que estudia el comportamiento de los seres humanos y lo refiere a un deber ser, es decir, a una serie de imperativos que, por su carácter universal, no sólo conciernen a todos, también garantizan - de diversas maneras- los ejercicios de voluntad, autodeterminación o libre albedrío, por mencionar algunos.

La continuidad de las sociedades organizadas se sustenta en las normas y principios que regulan ideas, moralidad y sentido común. El basamento ético resuelve las condiciones trascendentes de convivencia, los valores que rigen la consciencia y la conducta con el único objetivo del bien común. La idea ética proviene del ethos, éste, según los estudiosos de la materia, es la morada del ser humano, es decir, la actitud interior relacionada con la manera de ser y las costumbres. En este sentido, el ethos implica tanto causas como consecuencias de los actos, el modo de ser y el sentido de la vida en, por, para y desde la condición humana. Savater (2004) afirma que el vitalismo es la clave y el sustento para la comprensión de los preceptos de todas las éticas que, en el fondo, lo que buscan es la supervivencia del ser humano cuya naturaleza axiomática fue cuidadosamente explicada por Spinoza (2017). En este sentido, el mencionado filósofo ha analizado los afectos o pasiones del ánimo y los de la servidumbre humana, cuya comprensión conducen al entendimiento de la libertad, a través de grados del conocer, que a su vez dan sentido a la potencia de la razón para el ejercicio de la voluntad.

Es así como un aspecto del ser se transforma en deber ser y en "un querer radical, primordial, del cual deriven adecuada o inadecuadamente los restantes quereres humanos, creados de valores." (Savater, 2004, p. 298). Con lo antedicho se explica la paradoja de la libertad en la que el conatus o esfuerzo por preservar el ser, elegirá la conducta ética para regir la voluntad universal.

Desde el ethos se fundamenta y otorga validez a la moral y a los elementos que encauzan esa consciencia que regula lo que cada individuo lleva a cabo en libertad. El concepto de moral integra lo permisivo y lo coercitivo en preceptos organizados que delimitan el deber ser de grupos determinados culturalmente.

Los mores son las costumbres, esos hábitos que evolucionan en el tiempo y que las personas regulan conforme a sus aprendizajes acerca de la convivencia o de la identidad. Dichos hábitos trascienden de tal manera, que le son asignados calificativos morales, inmorales o amorales, dependiendo de su carácter o trasfondo y dan lugar a los denominados juicios de valor en calidad de testimonios, estimaciones, indicaciones o aprobaciones con sus correspondientes antinomias. Estos mores o hábitos delimitan preferencias y sus reglas 
se denominan normas morales, las cuales contribuyen a la generación de convergencias y afinidades sociales. (Konow, 2009, p. 27). Un juicio de valor evalúa la conducta al confrontarla con las normas vigentes.

En todo este complejo axiológico, se encuentra la consciencia como la capacidad de discernimiento moral de los seres humanos. Es la prescripción de aquellas acciones que evitan las divergencias con fines propios, de los otros o de un determinado contexto. La consciencia supone siempre:

[...] el reconocimiento del carácter normativo y obligatorio del comportamiento que llamamos moral [es la identificación] de una obligatoriedad que no le es impuesta desde fuera, sino que se la impone ella misma, aunque esta mismidad no sea absoluta en virtud de su carácter social [es por ello por lo que...] la conciencia moral efectiva es siempre la de un hombre concreto individual, pero, justamente por ello, de un hombre que es esencialmente social. (Sánchez Vázquez, 2007, p. 177)

La consciencia presenta una estructura compleja dada la urdimbre de los quehaceres morales y de los vínculos insoslayables que establece con la inteligencia, la voluntad, la experiencia, la educación, y con la suma de sentimientos, emociones, subjetividades contextuales y cultura en los que impacta tanto espacial como temporalmente. Desde la consciencia, los diseñadores, como todo ser humano, buscarán los criterios que les permitan distinguir lo correcto ante cada situación y cuál sería la conducta adecuada. Un diseñador - formado en el pensamiento ético - poseerá la perspicacia suficiente para optar por las acciones sensatas que resuelvan efectivamente una necesidad social.

En el diseño, como en todas las disciplinas, existe la certeza de que se cumplen reglas elementales para el bien propio y el de los demás. Y, es precisamente la consciencia ética, la que conduce a ese hacer autónomo. La observación de dichos principios se establece como hipotética o categórica. Siguiendo el primer imperativo - el hipotético- la premisa es que, si se quiere culminar de manera notable y asertiva un diseño, éste habrá de conllevar un beneficio a la sociedad. Es hipotético porque un diseñador puede pensar que no desea ser exitoso o notable, y ello le quitaría validez al supuesto. En la segunda posibilidad, regida por el imperativo categórico, no hay margen a condicionantes ni límites. Por ejemplo, ante el principio "enaltece tu profesión" no hay dobleces, frente a lo antedicho, el diseñador actúa con plena voluntad. Es por ello por lo que se considera a los imperativos categóricos como precedentes del deber ser ético del diseño.

Es importante considerar que, para la consciencia moral, la intencionalidad pierde valor si se actúa por una recompensa, y lo antedicho no se debe confundir con la legítima retribución por un trabajo, antes bien, se trata de la búsqueda de estímulos sociales, de reconocimiento, de estatus. En tal sentido, es interesante mencionar que:

[...] cada sistema moral es un paradigma, es decir, un modelo universal [y que un diseñador] recibe desde el exterior las normas [aunque en su interior] elabora las normas éticas que él mismo se otorga [...] (Gutiérrez, 2019, p. 69) 
También aquí cabe la idea de la noética que integra ese cúmulo de información ética que se graba en la memoria y que constituye un acopio personal, conforme al cual se reacciona frente a cualquier situación. Es decir, que constituye la guía interna que cada diseñador aplica para ser responsable de las consecuencias de sus actos cotidianos, y se reconoce tanto porque sigue el pulso de los valores adquiridos, como por constituir el resultado de los diversos aprendizajes. El desafío consiste en llevar estas acciones intuitivas a la dimensión de los actos conscientes, en los que se media entre la subjetividad y la objetividad, para llegar a un punto en el que la equivocidad y la univocidad no conduzcan a los extremismos. Desde esta comprensión, los primeros interesados en los argumentos explicativos de los valores deben ser los diseñadores, en sus empeños por aplicar los grandes principios éticos a la vida profesional, y en tanto ciencia de los valores morales. No se puede soslayar aquí esta necesaria mirada desde el diseño hacia los horizontes de la axiología o teoría de los valores. El valor es un constructo ontológico, y no por ello supra-empírico, atemporal, inmutable o absoluto tal como afirman Lotze, Hartmann y Scheler (Ruyer, 1974), es —antes bien-comprendido como el "bien adecuado". (Robles, 1952, p. 228)

El bien, bajo el aspecto de valor, está en la perspectiva de la causalidad formal, significa la cualidad intrínsecamente buena de algo; el bien bajo el aspecto de fin, está en la perspectiva de la causalidad final, significa el carácter de polarizados de la intencionalidad. (Beuchot, 2004, p. 128)

Llevado al plano del diseño, el bien entendido bajo el aspecto de fin, indica la dirección de la intencionalidad que responde a la necesidad, mientras que, entendido bajo el aspecto de valor, se evidencia en ese proceso proyectual que conduce a la consecución de lo diseñado. Por ello en la filosofía del diseño el valor es un aspecto trascendental, es el orden del diseño adecuado que se desplaza desde lo ontológico a lo axiológico donde el valor se presenta como una cualidad del diseño mismo en el que los mensajes, objetos o espacios adquieren un orden y cumplen una función.

La carga axiológica o valorativa, no depende únicamente del diseñador. También, en el diseño mismo se encuentran las dimensiones ontológica y axiológica; es decir, que lo diseñado primero es, y luego vale o es valioso y no en términos de valor de cambio, sino en términos de valor de signo. Más aún, el valor añade el sentido adecuado al diseño, es el bien adecuado de lo concreto en el que un factor o elemento trasciende como cualidad. El valor, desde la ética, se da en el diseño en la relación esencial y necesaria entre el diseñador y lo diseñado. $\mathrm{Si}$ bien no se no se reduce a ella, es un vínculo epistemológico y volitivo, dialéctico, que refleja la concreción de las ideas del diseñador en actos, para materializarse en el diseño mismo. Tanto el conocimiento como la concepción y volición en el diseño difieren de las de otras perspectivas éticas en que son trascendentales y predicamentales, ya que producen relaciones reales y tangibles. Así, los valores éticos en el diseño son producto del diseñador, devienen en constructos suyos, se dan en el encuentro con las necesidades y las intencionalidades. Cabe aclarar que no son valiosos porque el diseñador los considera así, al contrario, los considera así porque son intrínsecamente valiosos. Aquí, convergen las perspectivas subjetivas y objetivas que hacen de la ética del diseño un asunto hermenéutico, sujeto a interpretación con los límites y determinantes de una correcta hermenéutica analógica. También —como parte de 
la interpretación - surgen múltiples voces éticas, una de ellas es la que mira a los parámetros identitarios en el diseño y adquiere un papel central en los afanes por encontrar trayectorias históricas propias en los contextos del diseño. Lo cierto es que, como afirma Victoria Camps

[La ética] está adquiriendo un papel más central que el que tuvo en otros períodos históricos ¿razones? Sin duda varias. Quizá la más obvia sea la necesidad de reflexión sobre esta área de conocimiento que penetra en todas las demás áreas [es evidente] la urgencia de arbitrar consensos y darles una cierta validez. [En el diseño como en otras disciplinas] hay que seguir descansando en la razón, esa razón unitaria que nos llevará sin vacilaciones por la vía de la rectitud moral. (Camps, 2004, p. 26)

Una de las finalidades de la ética en el diseño ha de ser el establecimiento de un soporte firme de valores, que oriente la vida profesional y que se trate de valores compartidos, dirigidos hacia un diseño justo, solidario, de igualdad y respeto por sí, y por los otros. Es imprescindible que los valores éticos sean el sustento y soporte que motive el diseñar y lo que conlleva, la coexistencia con receptores, usuarios o habitantes, el beneficio y la responsabilidad social. Para que el diseño cuente con el perfil ético apropiado, se requiere la integración de un conjunto de circunstancias, entre las que se encuentran los valores éticos - que se exigen en la orientación de su actividad profesional—, el código deontológico - que establece las exigencias de la profesión-, las variables éticas no dependientes - que se marcan en los contextos de acción-, y la suma de factores a los principios éticos del diseñador. Lo anterior no significa que la ética profesional difiera en mucho de la ética universal, sólo se trata de su aplicación, expresada en deberes y principios expresos, nunca sobreentendidos, que se establecen como normas específicas para condiciones precisas.

El objetivo de la ética profesional es proveer recursos aplicados al proceder, cuya estructura es tan sólida que permite afirmar que, en el caso que nos ocupa, un diseñador es un interlocutor legítimo.

[...] goza de la circularidad propia de una hermenéutica crítica, ya que es en los distintos ámbitos de la vida social donde detectamos como trasfondo un principio ético [...] No se trata, pues, con la "aplicación" de aplicar principios generales a casos concretos, ni tampoco de inducir máximas desde las decisiones concretas, sino de descubrir en los distintos ámbitos la peculiar modulación del principio común [...] es lo que nos obliga a practicar la interdisciplinariedad. (Cortina, 2008, pp. 158-159)

La capacidad moral del diseñador radica en sus aptitudes para abordar y franquear su esfera profesional en horizontes más amplios, que dan valor al deber hacer, a lo diseñado. Contar con pilares éticos, le hará reconocer los actos reprobables o reprochables, que no tienen justificación alguna, que lo alejan del bien específico o bien diseñado. Los diseñadores alcanzan la madurez ética cuando su integridad está por encima de predisposiciones, posición, exaltación, etc., porque la probidad nunca está en juego. 
Cuando un diseñador egresa, pasa a formar parte de una comunidad con la cual se identifica, el sentido identitario se pone en juego y se comparte el estado social con el que se somete el gremio a la aceptación social. Se articulan necesidades y satisfactores propios de todo individuo productivo, hay derechos y deberes, se inicia el proceder ético que supone:

[...] respeto a la dignidad humana [...] proceder conforme a justicia, característica universal aplicable en las relaciones humanas [...] poner los conocimientos y habilidades profesionales al servicio del bien de los clientes o usuarios finales [...] proceder con conciencia y habilidades profesionales, esmerarse por ofrecer un servicio de calidad. (Cobo, 2001, pp. 73-101)

A lo antedicho, se añaden otras reglas como la responsabilidad social, la práctica leal, el ejercicio de criterios libres e imparciales respeto a los colegas y al diseño de otros, el fomentar el desarrollo y fortalecer al diseño con una imagen profesional digna o, cómo propone Elvira García, el cumplimiento de los principios de autonomía, tolerancia, responsabilidad, precaución, no maleficencia, beneficencia y justicia (2010, pp. 60-72). El trabajo de la ética del diseño debe ser interdisciplinario - como se mencionaba anteriormente - ya que así se integran visiones que enriquecen tanto procesos como resultados. En esta introducción no se soslayan las notables marcas que la pandemia del COVID-19 ha dejado en la humanidad, es una crisis en medio de la cual se ha elaborado este Cuaderno con todos los incidentes y dilemas que ello conlleva. Los textos, las correcciones y el resultado se generaron en confinamiento y con la satisfacción de concluir la labor bajo la premisa: todos estamos bien.

Tampoco se borran las huellas indelebles con las que esta experiencia ha marcado al diseño. Nunca - desde que el diseño es reconocido como una profesión legitimada - en las universidades, se habían evidenciado tantas carencias y omisiones del diseño. Por ejemplo, hay sistemas simbólicos universales desarrollados para transporte, cibernética, lenguajes diversos, industria, etc. No obstante, se adolece de un sistema universal de comunicación para contingencias sanitarias, y, en consecuencia, se testimonian esfuerzos improvisados de diseñadores - o no-, para elaborar comunicaciones infográficas. Lo antedicho pone en relieve que no existe la universalización simbólica y la unificación de criterios para identificar la realidad. También se han hecho públicas campañas erráticas y malogradas que han fracasado en su intento por desalentar la movilidad de la población, y se han vislumbrado esfuerzos aleatorios, que si bien algunos fueron muy asertivos, se han perdido en el océano de comunicación visual.

En este marco de pandemia, y a fin de dar cuenta de otras manifestaciones — en este caso de del diseño industrial fallido o ausente- han sido numerosas las imágenes - en todo el mundo- de rostros marcados de médicos, enfermeras y personal de salud por las impresiones de mascarillas y cubrebocas, la escasez de ventiladores sin prototipos viables; o también, en el área del diseño de indumentaria, se puede poner en relieve la falta de prendas adecuadas para transitar cómodamente en este contexto. Sin olvidar las limitadas posibilidades con las que demostraron contar los espacios hospitalarios para aislar pacientes o expandir servicios en un visaje al diseño arquitectónico y al de interiores. 
Sergio Cuevas postula que "ejercer una profesión es uno de los actos de mayor responsabilidad y compromiso social al que pueda aspirar el hombre" (2012, p. 13), no obstante, se requiere de una ardua preparación que, consecutivamente, certifica la capacidad de practicarla. En este sentido, es imprescindible la actualización a fin de comprender el curso de las necesidades, su mutación y el surgimiento de nuevas, tanto como tener claras las prioridades de acciones éticamente correctas. Particularmente, el diseñador tiene una gran responsabilidad social, al ser partícipe de procesos de comunicación y de mejora de mensajes, objetos y espacios, que desafían la superficialidad de tendencias y del styling. La gran masa diseñadora actúa en zonas cómodas y desahogadas sin buscar dar respuesta a los grandes retos sociales. Los diseñadores crean gran parte del mundo en el cual habitamos y se vinculan con ese universo de esperanzas que la humanidad trata de hacer realidad, dan forma a lo que se ve, a lo que se usa y a lo que se desperdicia (Berman, 2015, p. 1). El diseño es poder que influye, es dominio que se involucra permanente con los variados microcosmos, es autoridad en cómo los seres humanos conciben su presente y futuro, y también forma enlaces débiles, fuertes o nulos entre información, conocimiento y comprensión. Jorge Frascara (2004) describe a un diseñador activo y propositivo, con iniciativa, con capacidad técnica, metodológica y profesional, que dialoga interdisciplinariamente solucionando, así, necesidades y problemas sociales. El mencionado autor, afirma que no existe el presente sin historia y que no se comprende lo que vivimos si no se conocen las raíces. (Frascara, 2004). Hoy, un virus ha provocado que el género humano emita un grito desmoralizado hacia el diseño. La reflexión crítica siempre constituye un buen comienzo para revertir los errores disciplinares y en tal sentido la propuesta de este Cuadernos del Centro de Estudios en Diseño y Comunicación, como de toda reflexión académica, coadyuva al delineamiento de respuestas que iluminan contextos oscuros y desalentadores.

Concretamente, en el presente número, que tal como se sostuvo anteriormente, se propone un desafiante cruce entre ética, identidad y diseño. Las contribuciones que conforman este volumen se orientan en tres ejes: las visiones éticas sobre la práctica del diseño, las reflexiones teóricas acerca de la ética en el diseño y las disquisiciones en torno a la responsabilidad social y ética del diseño.

\section{Eje 1. Visiones éticas e identitarias sobre la práctica del diseño}

En este eje confluyen, por un lado, tres artículos que abordan el cruce entre la ética y la práctica del diseño, con los pueblos originarios. En primer lugar, en el texto intitulado Indumentaria indígena: ética, política y diseño. Una mirada sobre el artefacto vestimentario de la mujer chibuleo, la Dra. Aylen Medina Robalino estudia - a partir de un análisis histórico y etnográfico de la vestimenta del pueblo chibuleo (Ambato, Ecuador) - , a la indumentaria como artefacto de diseño, en la que leer sus inscripciones éticas, políticas e identitarias. El segundo aporte lo constituye el trabajo - Creación de la memoria iconográfica de una cooperativa de bordadoras indígenas, un ejercicio ético para el diseñadorde la Dra. Martínez Loera, en el que se reflexiona acerca de una experiencia con una 
cooperativa del municipio de Chilón (Chiapas, México). En su artículo, da cuenta de las implicancias éticas que devinieron, por un lado, de la conservación de los saberes de las mujeres indígenas de la cooperativa, quienes referenciadas en la flora y la fauna de la región, bordaron diversos diseños. Por el otro, destaca que se ha ahondado sobre el sentido simbólico de estos diseños y procurado utilizar éstos según las decisiones y propósitos de estas bordadoras. En tercer término, se inscribe la pesquisa de Eugenia Álvarez Saavedra - Uso del color y patrones geométricos en los diseños Mapuche contemporáneos: Adaptación semiótica en tres casos de estudio comparados - en cuyo aporte añade un interesante cruce de indagación en clave de emprendedorismo.

Dentro de este mismo eje, pero con un acento diferencial, centrado en la comunicación visual de la sociedad occidental, se consignan otras dos colaboraciones. El trabajo de la Dra. Dora Ivonne Alvarez Tamayo - Si la marca fuera una persona: análisis semiótico analógico- que indaga acerca de los valores semánticos de la marca y de los factores similares con la persona, relativos al ser, esencia y sentido. De allí que el artículo invite a preguntarse sobre el ser, como un quehacer constante y prioritario de las marcas y lo que representan, desde la ética, para no traicionar su esencia. Por su parte, Diseño, tipografía y comunicación visual. Ahora todo vale del Dr. Gerardo Gómez Romero, analiza al Diseño Gráfico y la tipografía, desde una perspectiva histórica, proponiendo una reflexión ética con respecto al desempeño profesional, y a las implicaciones pragmáticas, semánticas y sintácticas basada en el análisis de casos.

\section{Eje 2. Reflexiones teóricas acerca de la ética en el diseño}

Este eje está compuesto por tres trabajos. En primer lugar, el aporte de la Dra. Luz del Carmen Vilchis, con su texto Abstracciones filosóficas acerca del ethos del Diseño, analiza con profundidad, por un lado, cómo en pos de principios de mercado se ha dejado relegada cierta ética en el diseño. Para ello - y como parte de su propuesta analítica- primero estudia qué es el ethos en el diseño y cómo constituye el camino ético a retomar para el tan mentado bien común al que aspira el diseño. En sintonía con este planteo, en Reflexiones acerca de la identidad, la ética y la memoria en el diseño gráfico del Dr. Omar Lezama Galindo, se echa luz en la articulación de las tres variables mencionadas en el título y su incidencia en la responsabilidad de las decisiones profesionales que tendrán, invariablemente, impacto en el futuro y confluirán en la construcción de un perfil profesional íntegro de la comunicación visual. Por último, dentro de este Eje, las Dras. Elia del Carmen Morales González y Yésica Alejandra del Moral Zamudio, en su estudio titulado Consideraciones reflexivas para la acción del diseñador a partir de la ética y la identidad reflexionan sobre el Diseño, asumiéndolo en tanto acción propositiva que se imbrica con la ética y la identidad al involucrar necesariamente a un otro. De este modo, según sostienen las autoras, se genera una trilogía donde la acción, dirigida a resolver una necesidad, surgida del conocimiento del otro, es resuelta mediante la participación del diseñador que, produce una serie de fases que contribuyen al desarrollo del proceso de diseño. 


\section{Eje 3. Disquisiciones en torno a la responsabilidad social y ética del diseño}

En este último eje, se congregan tres artículos, que proponen el cruce analítico en relación con la formación del diseñador. En efecto, el texto La identidad del Diseñador Gráfico del siglo XXI y la exigencia de la responsabilidad social universitaria de las Dras. Flor de María Gómez Ordoñez y María Teresa Alejandra López Colín estudia el delicado equilibrio entre educar en la ética profesional y conforme la Responsabilidad Social Universitaria y responder a las expectativas del mercado. Dentro de la misma perspectiva, pero particularmente sobre la formación de posgrado, se inscribe la colaboración de Dr. Leobardo Armando Ceja Bravo - La otredad subyacente como creencia. Una reflexión ética, política $y$ formativa en diseñadores de posgrado-. Por último, en el texto Valores y responsabilidades del Diseño en la era de lo "hiper", la Dra. Martha Gutiérrez Miranda reflexiona sobre las transformaciones acaecidas de la mano de la llegada de la tecnología que - si bien no son privativas del diseño-, ameritan ser estudiadas en tanto fenómeno que atraviesa a todas las disciplinas tal como han sido concebidas hace más 100 años. Dichos cambios, según sostiene la autora, impactaron en la manera de asumir la profesionalización de la disciplina y, en tal sentido, conllevan una reformulación ética y epistemológica en torno a la identidad profesional, tanto respecto de su representación, como de su auto-concepto.

\section{Lista de Referencias Bibliográficas}

Berman, David (2015) Haz el bien diseñando. México: Designio

Beuchot, Mauricio (2004) Ética. México: Editorial Torres Asociados

Camps, Victoria (2004) Presentación en Camps, V. y otros. Concepciones de la ética. Madrid: Trotta.

Cobo Suero, Juan Manuel (2001) Ética Profesional en Ciencias Humanas y Sociales. Madrid: Huerga y Fierro

Cortina, Adela y Martínez, Emilio (2008) Ética. Madrid: Akal

Cuevas (2012) Ética y comportamiento profesional en Cuevas, S. y J. Peypoch. Cómo y cuánto cobrar diseño gráfico en México. España: Gustavo Gili

Frascara, Jorge (2004) Diseño gráfico para la gente, comunicación de masas y cambio social. Buenos Aires: Infinito.

García González, Dora Elvira (2010) Ética, profesión y ciudadanía. México: Porrúa / Tecnológico de Monterrey

Konow, James y otros (2009) Morals and Mores: Experimental Evidence on Equity and Equality, s/datos, www.researchgate.net/publication/4820745

Robles, O. (1952) Propedéutica filosófica. México: Porrúa

Ruyer, R. (1990) Filosofía del valor. México: FCE

Sanabria, José Rubén (2004) Ética. México: Porrúa.

Sánchez Vázquez, Adolfo (2007) Ética. México: DeBolsillo / Penguin Random House Grupo Editorial. 
Savater, Fernando (2004) Vitalismo en Camps, Victoria y otros. Concepciones de la ética. Madrid: Trotta.

Spinoza, Baruch (2017) Ética. Sevilla: Espuela de plata. Ediciones Renacimiento.

\begin{abstract}
This edition of Cuadernos del Centro de Estudios en Diseño y Comunicación is part of the Research in Design line. Precisely, this issue brings together academic contributions that establish epistemological correlations in the broad framework of ethics, identity and design, reviewing convergences and divergences in the actions of designers within the framework of a task that seeks to establish parameters of professional conduct. The works that make up this volume have been grouped into three areas. On the one hand, the ethical visions that reflect on the practice of design as a professional exercise and its articulation with indigenous peoples; and also with respect to its historical transformations. On the other hand, the theoretical reflections about ethics in design, both in key of the ethos of the designed, as well as in relation to the challenges that postmodernity and the market propose to this ethos. Finally, the disquisitions around the social responsibility and ethics of design, propose an analysis of the challenges that ethically entails the formation of new generations of designers in the university environment of degree and postgraduate.
\end{abstract}

Keywords: ethics - identity - design - research.

Resumo: Esta edição de Cuadernos del Centro de Estudios en Diseño y Comunicación faz parte da linha de Investigação em Design. Precisamente, esta edição reúne contribuições acadêmicas que estabelecem correlações epistemológicas no amplo marco da ética, identidade e design, revisando convergências e divergências nas ações dos designers dentro de uma tarefa que busca estabelecer parâmetros de conduta profissional. Os trabalhos que compõem este volume foram agrupados em três áreas. Por um lado, as visões éticas que refletem sobre a prática do design como exercício profissional na sua articulação com os povos indígenas e também no que diz respeito às suas transformações históricas. Por outro lado, as reflexões teóricas sobre ética no design, tanto em chave do ethos do design, como em relação aos desafios que a pós-modernidade e o mercado propõem a este ethos. Finalmente, as disquisições em torno da responsabilidade social e ética do design, propõem uma análise dos desafios que eticamente envolvem a formação de novas gerações de designers no ambiente universitário de graduação e pós-graduação.

Palavras chave: ética - identidade - design - pesquisa.

[Las traducciones de los abstracts fueron supervisadas por el autor de cada artículo] 